\title{
Acanthaceae Juss. no Parque Estadual Restinga de Bertioga, Estado de São Paulo, Brasil ${ }^{1}$
}

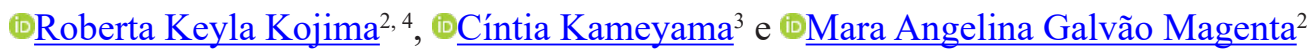

Recebido: 8 maio 2018; aceito: 23 novembro 2018

Como citar: Kojima, R.K., Kameyama, C. \& Magenta, M.A.G. 2019. Acanthaceae Juss. no Parque Estadual Restinga de Bertioga, Estado de São Paulo, Brasil. Hoehnea 46: e46018. http://dx.doi.org/10.1590/2236-8906-46/2018.

\begin{abstract}
Acanthaceae Juss. in Parque Estadual Restinga de Bertioga, São Paulo State, Brasil). Restinga is a costal vegetation with different physiognomic communities, determined by abiotic factors, such as topography and fluvial-marine influence. There are few works on restinga floristic composition of the central coastline of Sao Paulo State, and a small number of them report the occurrence of Acanthaceae in this ecosystem, none with species description. Ten species of the following genera were found in Parque Estadual Restinga de Bertioga: Aphelandra, Avicennia, Brillantaisia, Justicia, Hygrophila, Herpetacanthus, Lepidagathis and Ruellia. We present an identification key for the species, descriptions, information about the habitat and distribution, and photographs of the species.

Keywords: Acanthoideae, Lamiales, mangrove, São Paulo central coastline
\end{abstract}

RESUMO - (Acanthaceae Juss. no Parque Estadual Restinga de Bertioga, Estado de São Paulo, Brasil). A vegetação de restinga é formada por comunidades costeiras diversificadas, determinadas por fatores abióticos, como a topografia e a influência flúvio-marinha. As informações sobre a composição florística das restingas do litoral central do Estado de São Paulo são deficientes, poucos trabalhos referem a ocorrência de Acanthaceae nesse ecossistema e, quando o fazem, não há descrição das espécies. Foram encontradas dez espécies dos seguintes gêneros no Parque Estadual Restinga de Bertioga (PERB): Aphelandra, Avicennia, Brillantaisia, Justicia, Hygrophila, Herpetacanthus, Lepidagathis e Ruellia. Este trabalho apresenta uma chave de identificação das espécies, descrições, informações sobre habitat e distribuição geográfica e fotografias das espécies.

Palavras-chave: Acanthoideae, Lamiales, litoral central de São Paulo, manguezal

\section{Introdução}

A vegetação de restinga ocorre sobre depósitos arenosos costeiros e atua na estabilização do substrato, protegendo-o contra a ação dos ventos. Representa um conjunto de comunidades fisionomicamente distintas que, sob influência flúvio-marinha e marinha, variação topográfica e condições ambientais diversificadas e favoráveis, propiciam a formação de uma flora com ampla biodiversidade (Araújo \& Henriques 1984, Cerqueira 2000). As espécies que colonizam as restingas são provenientes de outros ecossistemas, especialmente os de outras formações vegetais da Mata Atlântica, porém com variações fenotípicas de seu ambiente original. Em razão do longo e contínuo tempo de ocupação e urbanização, as restingas, planícies arenosas de todo o litoral brasileiro, encontram-se alteradas ou parcialmente degradadas, o que dificulta a identificação da vegetação primitiva deste ecossistema (Lacerda \& Esteves 2000).

Assis et al. (2011) afirmam que a baixa similaridade florística entre as florestas de restinga do Sul e Sudeste brasileiros reforça a ideia de uma grande heterogeneidade da Planície Costeira nessas regiões.

$\mathrm{Na}$ parte sul do litoral sudeste brasileiro, que compreende o Estado de São Paulo e o sul do Estado do Rio de Janeiro, a costa se apresenta cheia de pequenas enseadas, com praias estreitas e costões rochosos. Segundo Pereira \& Araújo (2011), essa área apresenta escarpas íngremes formadas pelo Parque Estadual da Serra do Mar, que impedem o desenvolvimento

1. Parte do Trabalho de Conclusão de Curso da Primeira Autora

2. Universidade Santa Cecília, Rua Dr. Césario Mota 8, laboratório 82A, 11045-040 Santos, SP, Brasil

3. Instituto de Botânica, Núcleo de Pesquisa Curadoria do Herbário, Avenida Miguel Stéfano, 3687, 04301-902 São Paulo, SP, Brasil

4. Autor para correspondência: keylakoji@gmail.com 
de planícies costeiras. Estas condições fisionômicas caracterizam um litoral amplamente recortado, com numerosas enseadas e ilhas. As fisionomias em restingas do Estado do Espírito Santo e norte do Estado do Rio de Janeiro apresentam diferenças peculiares entre si, apesar da similaridade com relação às localizações geomorfológicas das formações (Pereira \& Araújo 2000, Magnagago et al. 2011). Zaluar \& Scarano (2000) relataram a presença de uma formação peculiar: as restingas de moitas, no Estado do Rio de Janeiro. Essas peculiaridades ambientais, incluindo influências marinhas, costeiras e de variabilidade topográfica, proporcionam ampla diversidade de comunidades vegetais (Araújo 1984).

Martins et al. (2008) destacam que as informações sobre as comunidades vegetais da flora em restinga para o litoral central do Estado de São Paulo ainda são escassas, diferente do que ocorre no litoral dos Estados do Rio de Janeiro e do Espírito Santo, que possuem diversos levantamentos florísticos e descrições dessa flora (Pereira \& Araújo 2000). Assim, existe uma lacuna de conhecimento a ser preenchida sobre a vegetação das restingas do litoral paulista.

Uma das famílias de plantas herbáceas a arbustivas encontradas nesse ecossistema é Acanthaceae. De maneira geral, Acanthaceae pode ser caracterizada por apresentar folhas opostas, flores pentâmeras com corola zigomorfa e gamopétala, androceu oligostêmone e fruto com cápsula loculicida e deiscência explosiva. É considerada monofilética baseada nas bases de sequência de ndhF, rbcL, trnLF, apesar de não apresentar sinapomorfias morfológicas (Judd et al. 2009). Estudos filogenéticos baseados em dados moleculares, associados a estudos relacionados à morfologia do pólen, assim como características da morfologia externa, foram utilizados como ferramentas para a delimitação da família. Atualmente, Acanthaceae é composta de 4 subfamílias: Acanthoideae, Avicennioideae, Nelsonioideae e Thunbergioideae (Schwarzbach \& McDade 2002, McDade et al. 2008, APG IV 2016).

Apesar de sua distribuição pantropical e da grande representatividade da família no Brasil, o reconhecimento específico de seus representantes nacionais se torna muito difícil, devido à inexistência de trabalhos taxonômicos recentes e abrangentes. Devido a isso, muitas espécies brasileiras ainda se encontram mal delimitadas, com nomenclatura desatualizada e problemas de tipificação. Este fato reforça a necessidade da realização de estudos que ajudem a elucidar as questões de delimitação específica, bem como de se empenhar esforços para identificar os representantes da família ocorrentes nos diversos biomas brasileiros.

Em relação aos estudos florísticos desenvolvidos nas restingas da Região Sudeste brasileira e que relatam a presença de representantes de Acanthaceae, deve-se destacar os de Silva \& Oliveira (1989), na restinga de Maricá (RJ); Pereira \& Araújo (2000), em restingas dos Estados de Espírito Santo e Rio de Janeiro; Moura et al. (2007), em de restingas de São Vicente (SP); Martins et al. (2008), na restinga de Bertioga; Kameyama \& Hirao (2015), na Ilha do Cardoso (SP); Braz et al. (2013), na restinga da Praia das Neves (ES) e Braz \& Azevedo (2016), que realizaram o tratamento taxonômico de Acanthaceae da Ilha de Marambaia (RJ).

No trabalho de Martins et al. (2008), representantes da família foram encontrados sobre cordões arenosos e vegetação associada às depressões. Em complemento ao trabalho desses autores, essa pesquisa objetivou a investigação florística da família no Parque Estadual Restinga de Bertioga - PERB, com descrição de gêneros e espécies, informações sobre habitat e distribuição geográfica, fotografias das espécies, além da elaboração de chave de identificação desses táxons.

\section{Material e métodos}

A área de pesquisa localiza-se na região norte do município de Bertioga - SP, compreendidas entre as coordenadas geográficas $23^{\circ} 44^{\prime} 23^{\circ} 46^{\prime} \mathrm{S}$ e $45^{\circ} 55^{\prime} 46^{\circ} 02^{\prime} \mathrm{W}$, dentro dos limites do Parque Estadual da Restinga de Bertioga. (figura 1). O PERB foi criado em 2010 e gerido pela Fundação Florestal, abrange uma área de 9.312,32 hectares, totalmente inserida no município de Bertioga (SP). É caracterizado pela alta conservação de fisionomias vegetais, alto grau de ameaça à sua integridade e forte mobilização da sociedade para sua proteção, constituindo importante corredor biológico composto por ambientes marinhocosteiros, incluindo manguezal, restinga e pelo Parque Estadual da Serra do Mar, garantindo, assim, a proteção fundamental para a perpetuidade dos seus processos ecológicos e fluxos gênicos (Fundação Florestal 2017).

O período do estudo foi entre 2014 e 2016 . As coletas de material botânico foram efetuadas nas fisionomias de vegetação sobre cordões arenosos (Floresta Alta de Restinga) e vegetação associada às depressões (Floresta Paludosa), estabelecidas pela Resolução CONAMAn. 7/96. Alguns materiais foram 


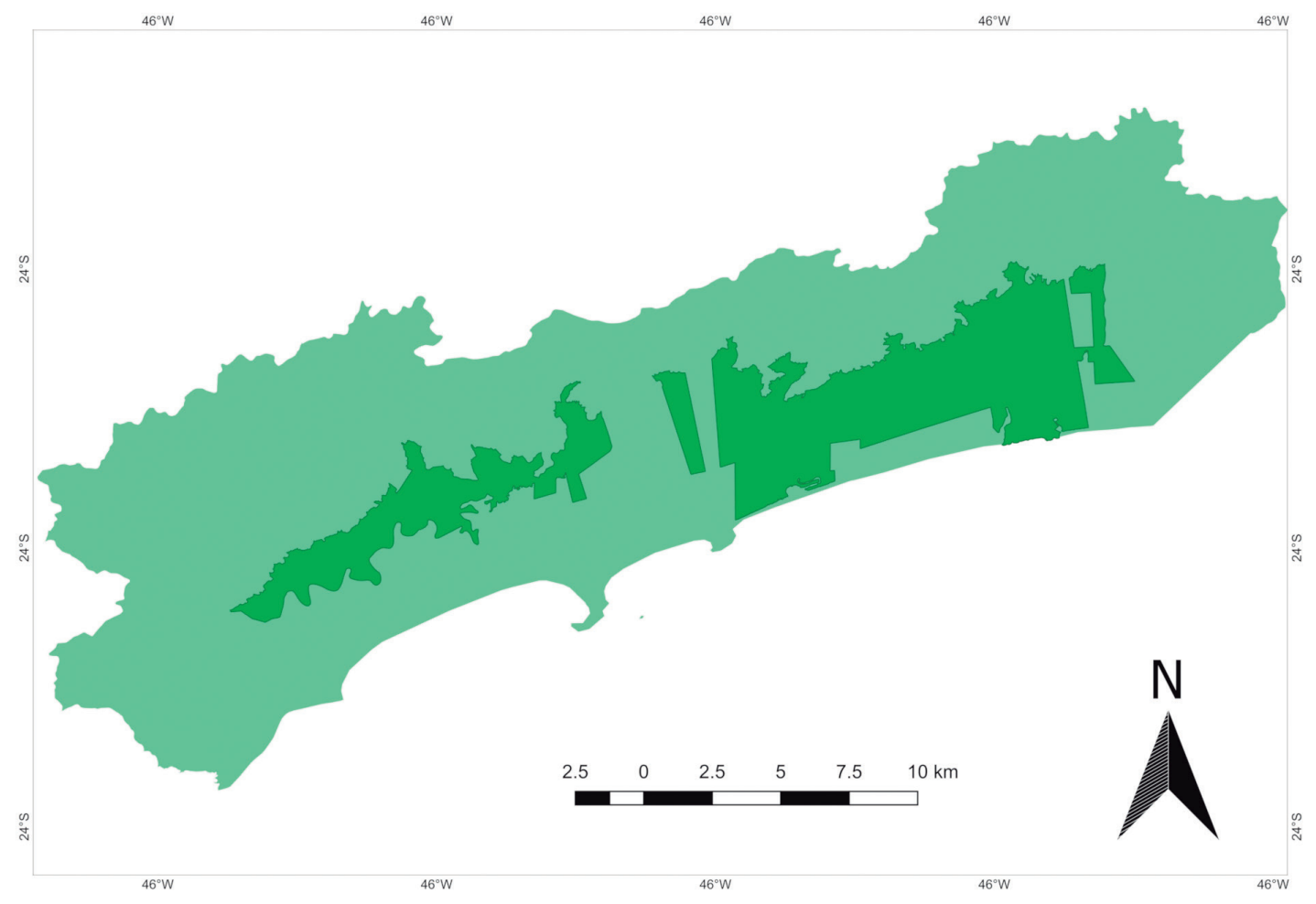

Figura 1. Mapa da cidade de Bertioga (verde-claro), São Paulo, e área do Parque Estadual Restinga de Bertioga (verde-escuro).

Figure 1. Map of the city of Bertioga (light green area), São Paulo State, and the Parque Estadual Restinga de Bertioga (dark green).

coletados no condomínio Riviera de São Lourenço, localizado fora das delimitações do Parque, e incluídos à lista de material examinado deste trabalho. Também foram incluídas duas espécies que, embora não tenham sido coletadas dentro do PERB, ocorrem em restingas de áreas próximas, com probabilidade de também ocorrerem dentro do Parque. As exsicatas estão depositadas no Herbário da Universidade Santa Cecília (HUSC), com doações para o Instituto Florestal (SPSF).

A caracterização morfológica das espécies foi realizada com base em plantas obtidas no trabalho de campo e nas coleções de Acanthaceae depositadas nos acervos dos herbários HUSC, SP, SPF e UEC. Foram utilizados materiais de outras localidades para complementar as descrições quando necessário, esses materiais são citados como material adicional examinado. A identificação dos táxons foi efetuada com uso de bibliografia específica. Os autores dos táxons foram citados conforme Brummitt \& Powell (1992). A distribuição das espécies foi obtida em bibliografia especializada e em informações de coleções de diversos herbários nacionais e internacionais, disponibilizados no banco de dados do INCT - Herbário Virtual de Flora e Fungos (2017).

\section{Resultados e Discussão}

\section{Acanthaceae Juss.}

Arbustos, subarbustos, ervas, escandentes ou eretas, um pouco menos comum, lianas trepadeiras e mais raramente árvores, comumente com cistólitos nos órgãos vegetativos. Folhas decussadas, simples, geralmente íntegras, sem estípulas. Flores hermafroditas, raramente solitárias, inflorescência variadas, em geral com brácteas e um par de bractéolas, flores pentâmeras, corolas gamopétalas, zigomorfas, geralmente bilabiadas; androceu oligostêmone, estames geralmente quatro, didínamos, ou dois; ovário súpero, bicarpelar, bilocular, óvulos 2-10 por lóculo. Fruto, em geral cápsula loculicida de deiscência explosiva e sementes sustentadas por um funículo desenvolvido e lignificado chamado de retináculo.

A família Acanthaceae compreende cerca de 220 gêneros com 4000 espécies amplamente 
distribuídas nos trópicos e pouco representadas em regiões temperadas (Stevens 2001), ocupando predominantemente o interior de matas mesófilas. No Brasil, a família é constituída, aproximadamente, por 40 gêneros e 450 espécies, cinco gêneros e 251 espécies endêmicas; ocorre em praticamente todas as formações vegetais, principalmente nos domínios das florestas pluviais. No Estado de São Paulo, são citados 19 gêneros e 77 espécies, com 18 gêneros e 69 espécies ocorrendo no Domínio da Mata Atlântica (Flora do Brasil 2020 em construção).

Martins et al. (2008) listaram, para o Parque Estadual Restinga de Bertioga, oito táxons distribuídos em seis gêneros (portanto, 1/3 dos gêneros encontrados no Domínio da Mata Atlântica do Estado de São Paulo), com Acanthaceae se destacando como a quarta família mais rica do estrato herbáceo. Neste trabalho, foram confirmadas duas identificações duvidosas de Martins et al. (2008) e acrescentada a identificação de Lepidagathis kameyamana Gnanasek. \& Arisdason.

Na restinga de Bertioga foram encontrados os seguintes táxons: Aphelandra ornata (Nees) T. Anderson, Aphelandra prismatica (Vell.) Hiern, Avicennia schaueriana Stapf \& Leechm. ex Moldenke, Herpetacanthus rubiginosus Nees, Hygrophila costata Nees, Justicia carnea Lindl., Justicia schenckiana Lindau, Lepidagathis kameyamana Gnanasek. \& Arisdason e Ruellia sp. A figura 2 mostra algumas das espécies estudadas.

\section{Chave de identificação para as espécies de Acanthaceae de Bertioga}

1. Hábito arbóreo. Pneumatóforos presentes. Pecíolo comprimido Avicennia schaueriana

1. Ervas ou subarbustos. Pneumatóforos ausentes. Pecíolo cilíndrico

2. Flor com dois estames

3. Cálice com segmentos iguais. Corola rosa ou púrpura. Tecas inseridas em alturas diferentes no conectivo 4. Folha lanceolada, com mais de $10 \mathrm{~cm}$ compr. Bráctea lanceolada Justicia carnea

4. Folha ovada, com até ca. $5 \mathrm{~cm}$ compr. Bráctea ovada Justicia schenckiana

3. Cálice com segmentos desiguais: anterior e posterior oblanceolados, laterais estreitotriangulares. Corola lilás. Tecas inseridas na mesma altura no conectivo ...... Lepidagathis kameyamana

2. Flor com quatro estames

5. Inflorescência em espiga

6. Bractéola 1-2,5 mm compr. Cistólitos ausentes. Corola amarela ou alaranjada. Todas as anteras monotecas

7. Folha 3,5-9,5 cm compr. Espiga com até $5 \mathrm{~cm}$ compr. Bráctea obovada com margem serrilhada nos $2 / 3$ superiores Aphelandra ornata

7. Folha 10-31,5 cm compr. Espiga com mais de $5 \mathrm{~cm}$ compr. Bráctea elíptica com margem inteira Aphelandra prismatica

6. Bractéola 6-7 mm compr. Cistólitos presentes. Corola lilás. Anteras anteriores bitecas e posteriores monotecas Herpetacanthus rubiginosus

5. Inflorescência em cimeira

8. Cimeira axilar congesta. Bráctea linear. Segmentos do cálice linear-triangulares. Corola alva, $8 \mathrm{~mm}$ compr. Hygrophila costata

8. Cimeira laxa, axilar ou terminal. Bráctea folhosa. Segmentos do cálice oblongoespatulados. Corola lilás, 3,5-6,8 cm compr. Ruellia sp.

\section{Aphelandra R. Br.}

Aphelandra é um gênero neotropical com, aproximadamente, 200 espécies (Profice \& Andreata 2011) que se estendem do Sul do México ao Norte da Argentina e Brasil. Representantes podem ser encontrados em altitudes de até 4000 metros acima do nível do mar; em geral apresentam endemismo relativamente alto, sendo comum sua ocorrência em áreas não perturbadas (Wasshausen 1975, Profice \& Andreata 2011). Aphelandra possui 44 espécies no território brasileiro, com 16 endêmicas, e oito espécies ocorrendo no Estado de São Paulo (Flora do Brasil 2020 em construção).

O gênero apresenta como caracteres diagnósticos: ausência de cistólitos; algumas espécies com folhas variegadas; inflorescência espiga decussada geralmente grandes e com cores vistosas, inclusive brácteas e bractéolas; margem da bráctea às vezes crenada ou serrilhada; (Wasshausen 1975); corola zigomorfa, geralmente bilabiada, quatro estames 

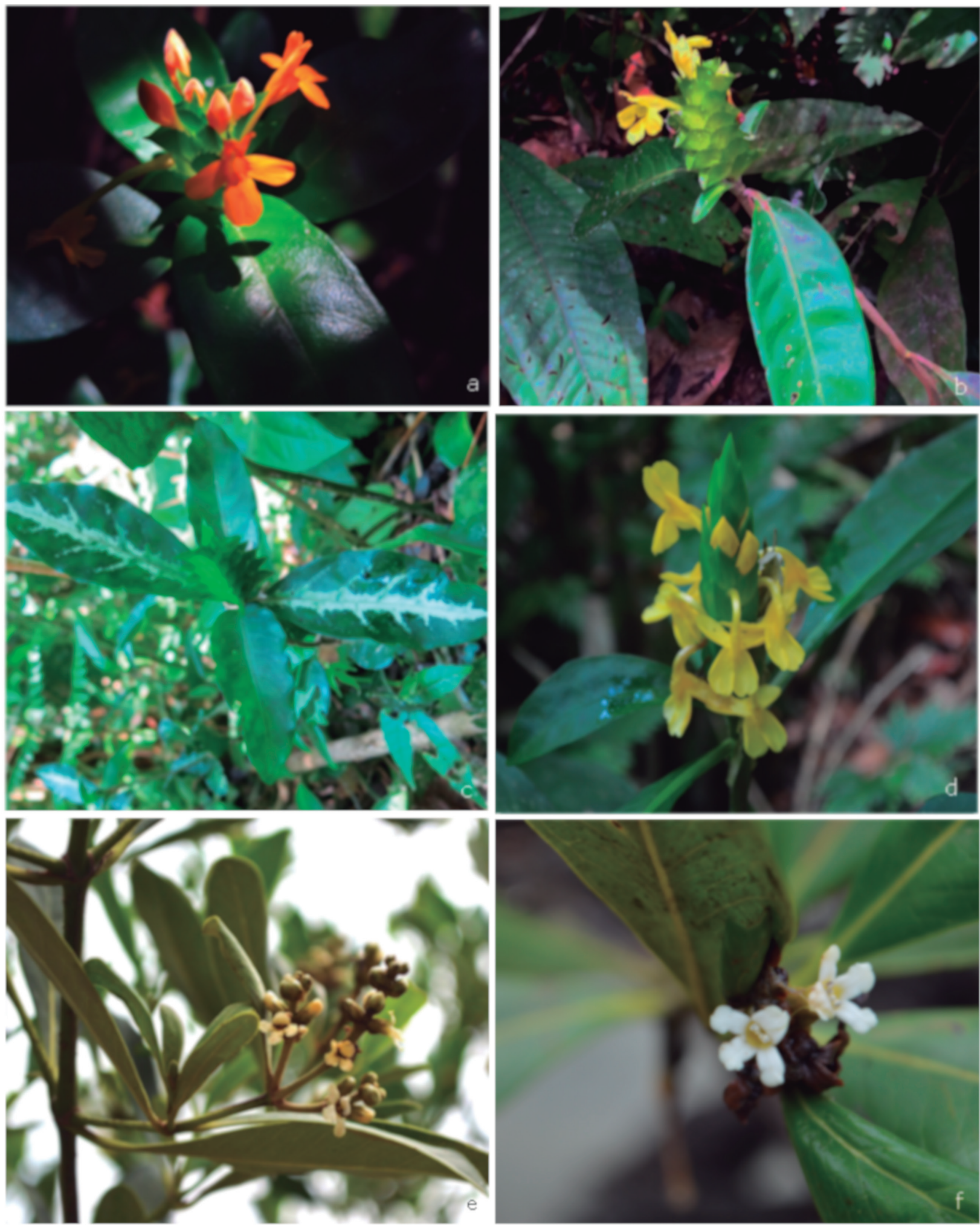

Figura 2. a-c. Aphelandra ornata (Nees) T. Anderson. a-b. Inflorescênia. c. Folha variegada. d. Aphelandra prismatica (Vell.) Hiern, inflorescência. e. Avicennia schaueriana Stapf \& Leechm. ex Moldenke, ramo florido. f. Detalhe da flor (Fotos: a,c. Mara A. G. Magenta. b. Roberta Keyla Kojima. d. Carlos Venicio Cantareli. e-f. Ulisses G. Fernandes).

Figure 2. a-c. Aphelandra ornata (Nees) T. Anderson. a-b. Inflorescense. c. Variegated leaf. d. Aphelandra prismatica (Vell.) Hiern, inflorescense. e. Avicennia schaueriana Stapf \& Leechm. ex Moldenke, flowered branch. f. Flower detail (Pictures: a, c. Mara A. G. Magenta. b. Roberta Keyla Kojima. d. Carlos Venicio Cantareli. e-f. Ulisses G. Fernandes). 
com anteras monotecas e grãos de pólen tricolpados. A forma da cápsula varia de obovada-estipitada a elipsoide, com quatro sementes dispostas sobre o retináculo (Profice \& Andreata 2011).

Aphelandra ornata (Nees) T. Anderson, J. Bot. 2: 289. 1864.

Figuras 2 f-i; 3 a

Erva $20-30 \mathrm{~cm}$ alt. Ramos híspidos. Folhas (3,5-) 4,5-8 (-9,5) × 1,4-4,7 cm, lâminas estreitoelípticas a ovadas, variegadas ou não, tricomas escassos, mais abundantes na face abaxial, concentrados na nervura central em ambas as faces, margem não ciliada, base decorrente, ápice agudo arredondado; pecíolo 0,7-1,5 cm compr., glabrescente. Espiga terminal, 4,2-5 cm compr.; brácteas obovadas $1-2 \times 1-1,4 \mathrm{~cm}$, margem serrilhada nos $2 / 3$ superior, ciliada, face abaxial com alguns tricomas; bractéolas estreito-triangulares, ca. $1 \times 1 \mathrm{~mm}$. Pedicelo floral 1-2 mm compr.; cálice $5 \mathrm{~mm}$ compr., segmentos $4 \mathrm{~mm}$ compr., lanceolados, cuspidados, pubescentes no ápice, margem ciliada; corola bilabiada, amarela a alaranjada, 1,8-3 cm compr., tubo basal 0,8-1,7 cm compr.; lábio anterior 3-lobado 0,7-0,9 × 0,9-1,2 cm, lobos 4-7 × 2-5 mm; lábio posterior 2-lobado (2-) 4-7 × 3,5-6 mm, lobos 1,5-2 × 1,5-2 mm; estames inseridos na fauce a $1,4 \mathrm{~cm}$ da base da corola, exsertos, 7,5-9 mm compr., filetes hirsutos no $1 / 3$ basal, estaminódios ausentes, anteras barbadas no ápice, com tufo de tricomas alvos, densos, oblongas, 2,5-3 mm compr; estilete 1,2-2,5 cm compr., estigma oblongotruncado, ca. 0,3 $\mathrm{mm}$ compr. Cápsulas obovadaestipitadas, ca. 1,3 cm compr; sementes orbiculares, marrons, pubescente com tricomas curtos, amarelos, $2 \times 1,5 \mathrm{~mm}$ diâm.

Em Bertioga, Aphelandra ornata foi coletada em estado fértil nos meses de outubro e novembro. No restante de sua distribuição, ela floresce ao longo do ano inteiro (INCT 2017).

Segundo Flora do Brasil 2020 em construção (2018), a espécie ocorre nas regiões Sudeste (Rio de Janeiro e São Paulo) e Sul (Paraná, Santa Catarina), no domínio fitogeográfico da Mata Atlântica, em Floresta Ombrófila.

Material examinado: BRASIL. S̃̃o PAULO: Bertioga, Bairro São Rafael, 25-X-2007, R.C. Forzza et al. 4825 (SP); Fazenda da Família Pinto, 13-X-1998, S.E. Martins et al. 297 (HUSC, SP); 13-X-1998, S.E. Martins et al. 289; Parque Estadual Restinga de Bertioga, Guaratuba, trilha de captação de água,
10-XI-2015, R.K. Kojima 4 (HUSC); idem, R.K. Kojima 5 (HUSC); idem, 14-XI-2015, R.K. Kojima 8 (HUSC); Praia de Boraceia, 27-XI-1989, E. Martins et al. 22548 (SP); Praia de Guaratuba, 8-XI-1997, E.C.P. Haller $\mathrm{s} / \mathrm{n}$ (SPF 124858); Praia do Itaguaré, 10-XI-1998, S.E. Martins et al. 322 (HUSC, SP); Rodovia Rio-Santos, km 204, 12-XI-2000, P. Fiaschi \& A.A. Eleutério 900 (SPF).

Material adicional examinado: BRASIL. SÃo Paulo: Cananeia, Parque Estadual da Ilha do Cardoso, 19-IV-1986, M. Sugiyama et al. 653 (SPF); Caraguatatuba, Parque Estadual da Serra do Mar, Núcleo Caraguatatuba, 7-IX-2000, R.S. Bianchini \& R.P.G. Rosario. 1369 (SP); Guarujá, 19-I-1913, A. C. Brade 6048 (SP); Iguape, Estação Ecológica de Chauás, 7-I-1999, E.R. Batista et al. 43 (SP); Miracatu, Fazenda Itereí, Serra de Paranapiacaba, 19-IV-1994, J.R. Pirani \& R.F. Garcia 3096 (SP); Pariquera-açú, Estação Experimental do Instituto Agronômico de Campinas, 5-IX-1994, E. Moncaio et al. 111 (SP); Pedro de Toledo, 28-IX-1961, J. Mattos 9153 (SP); Peruíbe, Estação Ecológica Juréia-Itatins, Serra da Juréia, 13-XII-1993, E.A. Anunciação \& R.J. Oliveira 416 (SP); Praia Grande, Vila Atlântica, 7-VI-1951, A.B. Joly 1100 (SP); Ubatuba, Parque Estadual da Serra do Mar, 20-I-2001, P. Fiaschi \& A. Lobão 570 (SPF).

Aphelandra prismatica (Vell.) Hiern, Vidensk. Meddel. Naturhist. Foren. Kjøbenhavn 1877-1878: 78. 1877.

Figuras 2 a

Subarbusto $60-70 \mathrm{~cm}$ alt. Ramos glabros. Folhas (10-) 21,8-31,5 × (3,2-) 6-8,5 cm, elípticas, glabras em ambas as faces, com raros tricomas nas nervuras da face abaxial, margem levemente ciliada, ocasionalmente serícea, base decorrente, ápice acuminado; pecíolo 1,5-3,5 cm compr. Espiga terminal 9,7-11,5 cm compr.; quadrangular, brácteas elípticas 1,8-2,4 × 0,7-0,9 cm, margem inteira, hialina, glabras, ápice agudo a curtamente lanceolado, bidentado; bractéolas oblongo-lanceoladas, $2,5 \times 1 \mathrm{~mm}$, com raros tricomas. Pedicelo floral 4-5 $\mathrm{mm}$ compr.; cálice 3,5-4,5 mm compr., quatro segmentos menores, 3-4 × 0,5-1 mm, um maior, 3-4 × 1,5-5 mm, oblongolanceolados, segmento maior com ápice arredondado e segmentos menores com ápice agudo, com alguns tricomas, margem glabra, unidos na base ca. $0,5 \mathrm{~mm}$ compr.; corola bilabiada, amarela, 3,5-4,7 cm compr.; tubo basal 2-2,5 cm compr.; lábio anterior 3-lobado, 
0,7-1,3 × 1,3-2 cm, lobo central 0,6-1,3 ×0,6-1,3 cm, laterais $0,6-1,2 \times 0,5-1 \mathrm{~cm}$, lábio posterior 2-lobado $0,6-0,8 \times 0,8-1 \mathrm{~cm}$, lobos 0,3-1 $\times 0,4-0,5 \mathrm{~cm}$; estames exsertos e inseridos na fauce, subdidínamos, $0,8 \mathrm{~cm}$ compr., inseridos a 1,7-1,8 cm da base da corola, hirsutos, estaminódio $1,7 \mathrm{~mm}$, anteras barbadas no ápice, com tufo de tricomas alvos, longos e densos, oblongas, 3,5-4 mm compr.; estilete ca. $3 \mathrm{~cm}$ compr., estigma bífido, lobos subclavados, subiguais, 0,2-0,3 mm compr.; disco nectarífero cupular. Cápsulas elipsoides, ca. $4 \mathrm{~mm}$ compr., sementes $4 \times 3 \mathrm{~mm}$ diâm., orbiculares, marrons, pubescentes, tricomas curtos, adpressos, amarelos.

Aphelandra prismatica floresce durante todo o ano (INCT 2017). Em Bertioga, foi coletada fértil entre abril e novembro.

Segundo Flora do Brasil 2020 em construção (2018), a espécie ocorre na região Sudeste (Espírito Santo, Rio de Janeiro, São Paulo), domínio fitogeográfico da Mata Atlântica, em Floresta Ombrófila.

Material examinado: BRASIL. SÃo PAulo: Bertioga, Guaratuba, 8-XI-1997, J.R. Pirani et al. s/n (SPF 124859); idem, Fazenda Três Marias, 20-V-1999, R.S. Bianchini \& S.E. Martins 1255 (HUSC, SP); idem, Loteamento Chácaras de Itapanhaú, 21-VIII-1995, S.L. Proença et al. 57 (SPF); idem, Parque Estadual Restinga de Bertioga, trilha de captação de água, 14-XI-2015, R.K. Kojima 7 (HUSC); Itaguaré, Fazenda da Família Pinto, 13-X-1998, S.E. Martins et al. 305 (HUSC, SP); idem, Rodovia Rio-Santos, km 204, 12XI-2000, P. Fiaschi \& A.A. Eleutério 901 (SPF).

Material adicional examinado: BRASIL. SÃo PAulo: Caraguatatuba, Parque Estadual da Serra do Mar, Núcleo Caraguatatuba, Trilha dos Tropeiros, 21-XI-2000, I. Cordeiro 2382 (SP, SPF); Cubatão, Parque Caminhos do Mar, Estrada Velha dos Santos, 21-XII-1994, S.A.C. Chie et al. 821 (SP); Mongaguá, III-1964, J. Mattos 11819 (SP); Peruíbe, Estação Ecológica, 9-VI-1983, L. Rossi \& I. Cordeiro s/n (SPF 46654); Santos, Área da Santa Casa de Misericórdia, 14-XII-2010, A. Indriunas \& R.J.F. Garcia 74 (SP); São Sebastião, Fazenda Jaraguá, 30-VI-1956, $M$. Kuhlmann. 3854 (SP); Ubatuba, Estação Experimental do IAC, 17-XI-1998, A.C. Marcato et al. 109 (SP, SPF); Estrada da Casa da Farinha, 30-I-1996, H.F. Leitão Filho et al. 34529 (SPF).

\section{Avicennia L.}

Avicennia é um gênero principalmente tropical, também com representantes nas regiões temperadas, reúne oito espécies (Tomlinson 1986). No Brasil e no Estado de São Paulo, ocorrem duas espécies (Flora do Brasil 2020 em construção).

O gênero pertence à subfamília Avicennioideae, grupo irmão de Thunbergioideae (Scotland \& Vollesen 2000, McDade et al. 2008). Foi relacionado à Verbenaceae no passado e elevado à categoria de família em classificações anteriores (Borg et al. 2008). São plantas arbóreas típicas de manguezais no Brasil e no mundo, altamente especializadas a esse ambiente. Possuem pneumatóforos, folhas especializadas para excreção de sal e se reproduzem por criptoviviparidade (Tomlinson 1986).

Avicennia schaueriana Stapf \& Leechm. ex Moldenke, Lilloa 4: 336. 1939.

Figuras 3 c, e

Árvores ou arvoretas 3-5m alt. Ramos glabros. Folhas 6,7-9,3 × 2,2-4,1 cm, elípticas a obovadas, glabras em ambas as faces, com glândulas circulares, mais densas na face abaxial, base aguda, ápice obtuso a arredondado; pecíolo comprimido, glabro, 0,5-1,5 cm. Dicásio paniculiforme terminal, 1,4-6 cm compr., raque denso-pubescente a incana, 1-2,8 cm compr.; brácteas e bractéolas subtriangulares, (4-) 6-10 × 2-3 mm, ápice agudo, base truncada, denso-pubescentes. Flor séssil; cálice 3-4 mm compr., segmentos unidos apenas na base, subtriangulares, ápice agudo a arredondado, base truncada, denso-pubescentes, margem ciliada; corola subinfundibuliforme, alva, 7-8,5 mm compr., tubo basal ca. 1,5 mm (1-2 mm), glabro, lobos laterais ca. $4 \times 1 \mathrm{~mm}$, ápice arredondado a subemarginado, posterior e anterior ca. 5-6 × 2-3 mm, ápice subemarginado, densamente pilosos externamente, estames 4, inclusos e inseridos no tubo, alternos aos lobos da corola; os posteriores 3,3-3,5 mm compr., os anteriores 2,3-2,8 mm compr., inseridos a ca. 3,1 mm da base da corola, glabros, anteras glabras, tecas paralelas entre si, oblongas, ca. $1 \mathrm{~mm}$ compr; ovário denso-hirsuto, estilete 1-1,5 mm, glabro, estigma bífido, lobos subiguais, subtriangulares, 0,5-0,7 mm compr; disco nectarífero cupular. Frutos uniloculares, univalvos, semente única cripto-vivípara.

Foi encontrado material fértil coletado em Bertioga entre novembro e junho. No restante de sua distribuição, Avicennia schaueriana floresce durante o ano inteiro (INCT 2017).

No Brasil, a espécie ocorre ao longo da costa, desde Santa Catarina até o Pará, em manguezais (Flora do Brasil 2020 em construção). 

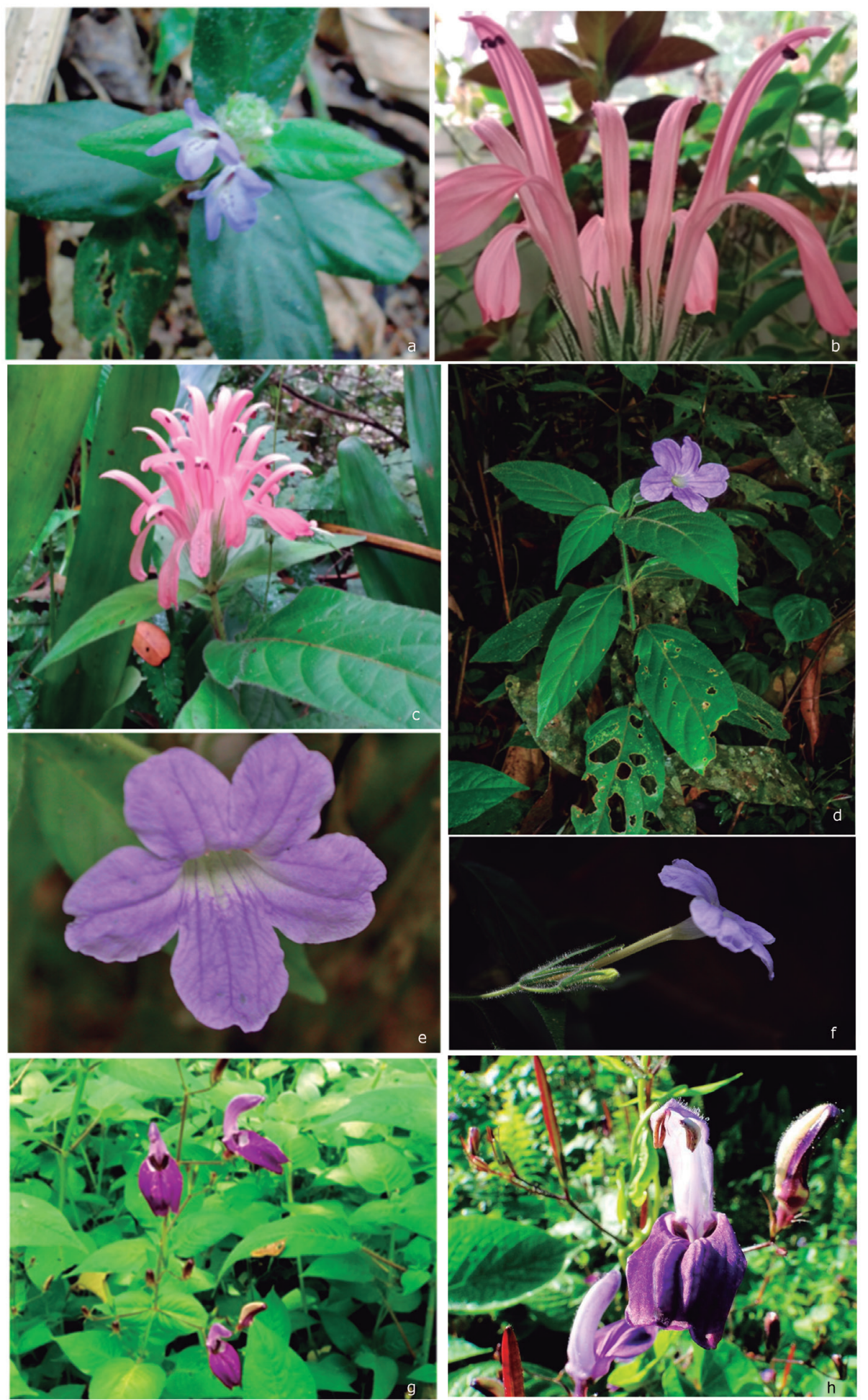

Figura 3. a. Herpetacanthus rubiginosus Nees, inflorescência. b-c. Justicia carnea Lindl., inflorescência. c. ramo florido. d. Ruellia sp., ramo florido. e. Corola em vista frontal. f. Corola em vista lateral. g-h. Brillantaisia lamium (Nees), ramo florido. g. Detalhe da flor (Fotos: a, g-h. Paulo S. Penteado Sampaio. b. Larissa Brandine Nascimento. c. Roberta Keyla Kojima. d. Suzana E. Martins. e. Mara A. G. Magenta. f. Ulisses G. Fernandes).

Figure 3. a. Herpetacanthus rubiginosus Nees, inflorescence. b-c. Justicia carnea Lindl., inflorescence. c. Flowered branch. d. Ruellia sp., flowered branch. e. Corolla in frontal view. f. Corolla in lateral view. g-h. Brillantaisia lamium (Nees), flowered branch. g. Flower detail (Pictures: a, g-h. Paulo S. Penteado Sampaio. b. Larissa Brandine Nascimento. c. Roberta Keyla Kojima. d. Suzana E. Martins. e. Mara A. G. Magenta. f. Ulisses G. Fernandes). 
Material examinado: BRASIL. SÃo PAUlo: Bertioga, 16-VI-1989, C.S. Zickel \& S.M. Salis 23475 (UEC); 5-11-1992, Menezes, N.L. s/n (SPF77876).

Material adicional examinado: BRASIL. SÃo PAULO: Cananeia, 30-IX-1961, J. Mattos 9160 (SP); Ilha do Cardoso, 15-II-1979, D.A. De Grande \& E.A. Lopes 276 (SP); 1-XI-2010, G.M. Mori \& P.M.F. Oliveira 2 (UEC); idem, G.M. Mori \& P.M.F. Oliveira 3 (UEC); Cubatão, 25-VII-1907, A. Usteri s/n (SP15598, JPB); Ilha Comprida, Pedrinhas, 23-VI-1999, N. Hanazaki et al. 177 (UEC); Itanhaém, 12-III-2006, R.J.F. Garcia et al. 2731 (PMSP, SP); Peruíbe, 9-X-1995, V.C Souza et al. 9316 (SP, UEC, HRCB, SPF, HUEFS); São Vicente, 10-VIII-1933, F.C. Hoehne \& H.N. Moldenke 30854 (SP, JPB); Ubatuba, Ilha Anchieta, 7-II-1996, H.F. Leitão-Filho et al. 34847 (SP, UEC, HUEFS); idem, Rio Escuro, 29-XI-2011, G.M. Mori \& P.M.F. Oliveira 19 (UEC).

\section{Herpetacanthus Nees}

Herpetacanthus é um gênero neotropical que abrange 18 espécies (Indriunas \& Kameyama 2012). No Brasil, está representado por 16 espécies, 14 endêmicas, e no Estado de São Paulo ocorrem quatro delas (Flora do Brasil 2020 em construção).

É composto por espécies subarbustivas a arbustivas, geralmente anisofílicas e se distingue pelo cálice com cinco segmentos subiguais; corola bilabiada com lábio posterior bidentado e lábio anterior trilobado; quatro estames didínamos, os anteriores com anteras bitecas, as tecas inseridas em diferentes níveis do conectivo, e os posteriores com anteras monotecas (Indriunas \& Kameyama 2012).

Herpetacanthus rubiginosus Nees, Fl. Bras. (Martius) 9: 94.1847 [1 Jun 1847].

Figura $2 \mathrm{~b}$

Subarbusto 5-30 cm. Ramos glabrescscentes; presença de raízes adventícias. Folhas (3,2-) 4,3-5,8 $\times$ 1,5-3,2 cm, elípticas, face adaxial híspida, face abaxial esparsamente pilosa, sobretudo na nervura, ou tricomas esparsos em ambas as faces, presença de cistólitos, margem ciliada ou não, base atenuada a decorrente no pecíolo, ápice agudo, arredondado ou mucronado; pecíolo 3-4 (-8) mm compr. Espiga terminal, 1,5-2 cm compr.; brácteas obovadas, $8-9 \times 5 \mathrm{~mm}$, híspidas, tricomas escassos nas nervuras, margem ciliada; bractéolas lanceoladas, 6-7 × $1 \mathrm{~mm}$, glabras, ápice mucronado, margem ciliada. Flor subséssil; cálice 2-2,5 cm compr., segmentos subiguais 6-9 mm compr., estreito-triangulares a lanceolados, agudos, unidos na base ca. $1 \mathrm{~mm}$, persistentes, presença de alguns tricomas, margem ciliada; corola bilabiada, $1,2-1,8 \mathrm{~cm}$ compr., lilás, lábio posterior com máculas roxas, tubo basal 3,5-5 cm compr., lábio posterior 4-7 × 2-5 mm compr., lábio anterior, 3-8 $\times$ 4-6 mm compr., lobos $2-5 \times 1-5 \mathrm{~mm}$ compr.; estames inclusos, inseridos no tubo basal, coniventes, maiores ca. $4 \mathrm{~mm}$ compr., menores ca. $2 \mathrm{~mm}$, esparso-pilosos, inseridos a 4-5 $\mathrm{mm}$ da base da corola, anteras oblongas, 07-1 $\mathrm{mm}$ compr.; estilete filiforme, 0,9-1,2 cm compr., estigma bífido, lobos lanceolados, ca. 0,2 mm compr.; disco nectarífero cupular. Cápsulas, elipsoides, ca. $1 \mathrm{~cm}$ compr; sementes 4 , ca. $2 \times 2$ mm diâm., orbiculares, papiladas.

Foi encontrado material fértil coletado em Bertioga entre agosto a outubro. No restante de sua distribuição, Herpetacanthus rubiginosus floresce entre julho e dezembro (INCT 2017).

No Brasil, a espécie ocorre na região Sudeste (Espírito Santo, Minas Gerais, Rio de Janeiro, São Paulo), domínio fitogeográfico da Mata Atlântica, em Floresta Ombrófila (Flora do Brasil 2020 em construção).

Material examinado: BRASIL. SÃo PAUlo: Bertioga, Guaratuba, Condomínio Guaratuba2, 22-VIII-1995, S.L. Proença 81 (SP); Riviera de São Lourenço, 20-X-1999, S.E. Martins 568 (HUSC, SP); São Lourenço, 2-IX-1999, P.S.P. Sampaio \& S.E. Martins 344 (HUSC, SP).

Material adicional examinado: BRASIL. SÃo PAULO: Caraguatatuba, Parque Estadual da Serra do Mar, Núcleo Caraguatatuba, 27-IX-2000, I. Cordeiro et al. 2332 (SP, SPF); 20-XI-2010, A. Indriunas \& C. Kameyama et al. 72 (SP); Santos, Área da Santa Casa de Misericórdia, 14-XII-2010, A. Indriunas \& R.J.F. Garcia 76 (SP); Ubatuba, Estação Experimental Agronômico, 12-XI-1993, D. Santin et al. 29914 (SPF); 18-XI-2010, A. Indriunas \& C. Kameyama et al. 58 (SP).

\section{Hygrophila R. Br.}

Hygrophila é um gênero cosmopolita, que abrange em torno de 100 espécies (Lioger 1997). Na Flora do Brasil 2020 em construção (2018) são citadas oito espécies, sendo duas para o Estado de São Paulo. No entanto, preferimos seguir o conceito de Daniel (1995) e considerar que na Região neotropical ocorre apenas uma espécie, $H$. costata Nees, que apresenta uma ampla distribuição e variação morfológica. 
O gênero compreende subarbustos e ervas eretos ou reptantes; inflorescência com flores desenvolvidas em feixes axilares; brácteas lineares; cálice com cinco segmentos, subiguais; corola bilabiada, tubo cilíndrico; quatro estames didínamos ou dois estames e dois estaminódios, os filamentos de cada par são unidos pela base por uma membrana, anteras bitecas, às vezes mucronadas; lobo posterior do estigma abortivo; cápsula oblonga, não estipitada; sementes 4-18 ou mais (Wasshausen \& Smith 1969, Durkee 1986).

Hygrophila costata Nees, P1. Hort. Bonn. Icon. 7 (t. 3). 1824.

Subarbusto ca. $1 \mathrm{~m}$ alt. Ramos com tricomas esparsos, cistólitos presentes. Folhas (5-) 7,5-18 (-21) ×(1-) 1,7-4 cm, elípticas a lanceoladas, sésseis, face adaxial com raros tricomas, face abaxial com tricomas tectores, sobretudo nas nervuras, base decorrente, ápice agudo. Cimeira axilar congesta (0,5-) 1,5-4,5 cm compr., com uma a muitas flores; brácteas lineares $(1,5-)$ 3,3-4 (-8) × 0,4-1,8 (-7) cm, face adaxial glabra, abaxial com alguns tricomas, cistólitos presentes. Flor séssil; cálice $0,6-1 \mathrm{~cm}$ compr., segmentos 5-8 $\times$ ca. 0,5 mm, linear-triangulares, ápice agudo, híspidos, margem ciliada; corola bilabiada, branca, ca. $8 \mathrm{~mm}$ compr.; tubo basal ca. $4 \mathrm{~mm}$ compr.; lábio posterior 2-lobado ca. $3 \times 1,5 \mathrm{~mm}$, lábio anterior 3-lobado $3 \times 2,5 \mathrm{~mm}$; estames 4 , exsertos, inseridos na fauce, maiores $3,5-4 \mathrm{~mm}$, menores $2-2,5 \mathrm{~mm}$, inseridos a 2-2,5 $\mathrm{mm}$ da base da corola, glabros, anteras $05-1 \mathrm{~mm}$ compr., tecas paralelas, oblongas, glabras; estilete ca. $5 \mathrm{~mm}$ compr., glabro, estigma 1-0,2 mm compr., bífido, lobos lanceolados, desiguais; disco nectarífero cupular. Cápsulas estreito-elípticas, 1-1,5 cm compr.; sementes 9-12, 1-1,3 × 1-1,1 mm, orbiculares, marrons com margem acastanhada e ciliada, tricomas higroscópicos.

Foi encontrada coleta de material fértil em Bertioga no mês de março. No restante de sua distribuição, Hygrophila costata floresce ao longo de todo o ano (INCT 2017).

A espécie apresenta distribuição neotropical (Silva 2011), ocorrendo por todo o Brasil, nos domínios fitogeográficos da Amazônia, Caatinga, Cerrado e Mata Atlântica, em Floresta Ciliar ou Galeria e Floresta Ombrófila (Flora do Brasil 2020 em construção).

Material examinado: BRASIL. SÃo PAUlo: Bertioga, São Lourenço, 18-III-1999, S.E. Martins et al. 410 (HUSC, SP).
Material adicional examinado: BRASIL. SÃo PAULO: Barra do Turvo, 14-II-1995, J.P. Souza et al. 71 (SP); Estrada de Acesso à Barra do Turvo, 8-II-1995; Cunha, Parque Estadual da Serra do Mar, Núcleo Cunha, 19-III-1996, M. Kirizawa et al. 3247 (SPF); Pariquera-Açú, Parque Estadual do Pariquera Abaixo, 7-I-1999, J.R.L. Godoy et al. 44 (SP); São Sebastião, Praia da Baleia, 23-IV-2000, J.P. Souza et al. 3424 (SPF); Ubatuba, Instituto Agronômico de Campinas, 1-II-1996, H.F. Leitão Filho et al. 34592 (SP).

\section{Justicia L.}

Justicia é o maior gênero de Acanthaceae, abrange cerca de 700 espécies (Graham, 1988, Ezcurra 2002), principalmente tropicais, com alguns representantes nas regiões temperadas. No Brasil há registro de 127 espécies e no Estado de São Paulo ocorrem 20 espécies (Flora do Brasil 2020 em construção). Embora Justicia seja sabidamente polifilético (McDade et al. 2000, Kiel et al. 2017) neste trabalho foi utilizado o conceito mais amplo do gênero (Graham 1988, Ezcurra 2002) enquanto se aguarda mais estudos relacionados a esse grupo.

O gênero é representado por espécies com folhas geralmente íntegras, raramente crenuladas ou crenadas, com cistólitos; inflorescência espiciforme, cimeira ou panícula, raramente flores solitárias; flor geralmente com uma bráctea e duas bractéolas, variadas em forma e cor; cálice profundamente partido; corola bilabiada, lobo anterior 2-lobado e posterior 3-lobado; androceu com dois estames, anteras bitecas, tecas em geral desiguais, apendiculadas ou não, estaminódios ausentes; fruto do tipo cápsula loculicida bivalvar, com quatro sementes ou reduzidas por aborto (Graham 1988, Ezcurra, 2002).

Justicia carnea Lindl., Edwards's Bot. Reg. 17: t. 1397. 1831.

Figuras $2 \mathrm{c}$

Subarbusto 0,7-1,5 m alt. Ramos híspidos. Folhas 10,5-17 × 4,5-7 cm, lanceoladas, face adaxial híspida com tricomas concentrados nas nervuras, face abaxial densamente híspida, margem ciliada, base decorrente a atenuada, ápice atenuado; pecíolo (0,5-) 1-2 cm compr. Panícula congesta (2-) 3,5-9,2 cm compr., séssil a subséssil, 12-18 (-24) flores; brácteas lanceoladas, $1,5-5(-12,8) \times 0,2-1,5(-4) \mathrm{cm}$, pubescentes, sobretudo nas nervuras, margem ciliada; bractéolas como as brácteas 1-3 cm compr. Pedicelo 2-4 mm compr.; cálice 5-9 mm compr., segmentos $4-8 \times$ ca. $0,5 \mathrm{~mm}$ compr., estreito-triangulares, atenuados, híspidos a 
pubescentes, margem ciliada; corola bilabiada, rosada, (2-) 2,5-5,7 cm compr.; tubo basal ca. $2 \mathrm{~cm}$ compr., lobos anteriores ca. $4 \times 2 \mathrm{~mm}$ compr., lobos posteriores ca. $4 \times 4 \mathrm{~mm}$ compr.; estames inclusos, inseridos na fauce, tecas inseridas em alturas diferentes, divergentes, teca inferior apendiculada, 2-2,5 mm compr.; estilete 2,3-5,7 cm compr., glabro, estigma levemente bilobado, lobos orbiculares, 0,1-0,2 mm compr.; disco nectarífero cupular. Frutos não vistos.

Tanto em Bertioga quanto no restante de sua distribuição, foi encontrado material fértil Justicia carnea ao longo do ano inteiro (INCT 2017).

No Brasil, a espécie ocorre nas regiões Sudeste (Espírito Santo, Minas Gerais, Rio de Janeiro, São Paulo) e Sul (Paraná, Santa Catarina, Rio Grande do Sul), domínio fitogeográfico da Mata Atlântica, em Floresta Estacional Semidecidual e Floresta Ombrófila (Flora do Brasil 2020 em construção).

Material examinado: BRASIL. SÃo PAULO: Bertioga, Fazenda da família Pinto, 13-X-1998, S.E. Martins et al. 304 (HUSC, SP); 29-IV-1999 P.S.P. Sampaio et al. 259 (HUSC, SP); idem, Guaratuba, Fazenda Três Marias, 10-XII-1998, P.S.P. Sampaio et al. 164 (SP); 10-XII-1998, S.E. Martins et al. 360 (SP); idem, Parque Estadual Restinga de Bertioga, trilha de captação de água, 10-XI-2015, R.K. Kojima 2 (HUSC); idem, R.K. Kojima 3 (HUSC); idem, 14-XI-2015, R.K. Kojima 6.

Material adicional examinado: BRASIL. SÃo PAULO: Barra do Turvo, Estrada de acesso à Barra do Turvo, 8-II-1995, H.F. Leitão Filho et al. 33115 (SPF); 14-II-1995, J.P. Souza et al. 84 (SPF); Cananéia, Ilha do Cardoso, 8-IX-1988, F. Barros et al. 1575 (SP); idem, 27-IX-1989, F. Barros 1752 (SPF); Caraguatatuba, 23-VI-1993, S. Buzato \& M. Sazima 28734 (SPF); Ilhabela, Parque Estadual de Ilhabela, Trilha da Toca da Goteira, 23-VIII-1995, A. Rapini et al. 46 (SPF); Iporanga, 23-IV-1994, V.C. Souza et al. 23-IV-1994 (SPF); Ubatuba, Estrada da Casa da Farinha, 30-I-1996, H.F. Leitão Filho et al. 34538 (SPF).

Justicia schenckiana Lindau, Bull. Herb. Boissier 3: 485.1895.

Figuras $3 \mathrm{~b}, \mathrm{~d}$

Ervas 10-35 cm alt. Ramos com duas linhas longitudinais de tricomas simples, com presença de raízes adventícias. Folhas 3,8-5,1 × 1,5-2,3 cm, ovadas, anisofílicas, face adaxial com alguns tricomas na nervura central, face abaxial com tricomas esparsos, margem ciliada, cistólitos presentes, base decorrente a oblíqua, ápice agudo arredondado; pecíolo (0,4-) 0,8-1,8 cm. Espiga terminal, (1,3-) 1,8-4,3 (-5,3) cm compr., pedúnculo 0,5-1,5 cm compr., ca. 8-20 flores, brácteas ovadas e subimbricadas, (1,2-) 2-5 $\times 0,6-2 \mathrm{~cm}$, face adaxial e abaxial com alguns tricomas, sobretudo na região da nervura, cistólitos presentes, margem ciliada; bractéolas lanceoladas, 4-6 $\times 0,5-2 \mathrm{~mm}$, pubescentes, margem híspida. Flor subséssil; cálice $0,7-1 \mathrm{~cm}$ compr., segmentos subiguais 3-5 (-9) mm compr., lanceolado-subulados, agudos, unidos na base em ca. $0,5 \mathrm{~mm}$ compr., com tricomas escassos, margem ciliada; corola bilabiada, púrpura, guia de néctar alvo, ocasionalmente com guia de néctar roxo, 6-12 mm compr., tubo basal 4-7 mm compr., lábio posterior 4-6 × 4-4,5 mm, lobos 1-4 × 0,5-2 mm, lábio anterior 1-2 $\times 1-3 \mathrm{~mm}$, levemente bilobado; estames inclusos, inseridos na fauce, $2,4 \mathrm{~mm}$ compr., glabros, inseridos a $5,3 \mathrm{~mm}$ da base da corola, conectivos alargados, tecas inseridas em alturas diferentes, sem apêndices, subiguais, curto-oblongas, 2-2,5 $\mathrm{mm}$ compr.; estilete ca. $7 \mathrm{~mm}$ compr., glabro, estigma levemente bilobado, lobos lanceolados, 0,1-0,2 mm compr.; disco nectarífero cupular. Cápsulas, elipsoides, estipitados, sementes $4,1,3 \times 1,3 \mathrm{~cm}$, orbiculares, marrons a acastanhadas, verrucosas.

Em Bertioga, foi coletado material fértil nos meses de setembro e outubro. No restante de sua distribuição, Justicia schenckiana floresce durante todo o ano (INCT 2017).

No Brasil, a espécie ocorre nas regiões Sudeste (São Paulo) e Sul (Paraná, Santa Catarina), no domínio fitogeográfico da Mata Atlântica, em Floresta Estacional Semidecidual e Floresta Ombrófila (Flora do Brasil 2020 em construção).

Material examinado: BRASIL. SÃo PAulo: Bertioga, Fazenda Três Marias, 16-IX-1999, E.S. Lima \& S.E. Martins 1 (HUSC, SP); Praia do Itaguaré, 21-X-1999, P.S.P. Sampaio \& J.A. Pastore 355 (HUSC, SP).

Material adicional examinado: BRASIL. SÃo Paulo: Barra do Turvo, 14-II-1995, J.P. Souza et al. 84 (SPF, UEC, HRCB, US); Cananeia, Ilha do Cardoso, 25-X-1989, I. Cordeiro et al. 570 (SP); idem, 14-XII-1983, C.F.S Muniz 514 (SP); Eldorado Paulista, Parque Estadual Jacupiranga, 9-II-1995, H.F. Leitão Filho et al. 32975 (SPF, HRCB, ESA); Iguape, Estação Ecológica Jureia-Itatins, M.P. Costa et al. 70 (SP); idem, 13-III-1990, M.C.H. Mamede et al. 224 (SP); idem, 19-II-1991, L. Rossi et al. 812 
(SP); idem, 21-II-1996, C. Bestetti-Costa et al. 139 (SP), idem, 18-XI-1987, M. Kirizawa et al. 1952 (SP); Serra da Jureia, 27-VI-1993, M.C.H. Mamede 540 (SP); idem, 12-XII-1990, S.J.C. Silva et al. 109 (SP); Sete Barras, 12-I-1999, J.R.L. Godoy et al. 105 (ESA, SP); 13-V-1993, S. Aragaki et al.76 (SP); Tapiraí, 18-X-1994, K.D. Barreto et al. 3040 (ESA, SP); Fazenda Intervales, 11-X-1994, M.L. Kawasaki et al. 658 (SP, SPF).

\section{Lepidagathis Willd.}

Lepidagathis tem uma distribuição pantropical e conta com cerca de 105 espécies (Kameyama 2008). O Brasil é representado por 14 espécies e no Estado de São Paulo existem três espécies (Flora do Brasil 2020 em construção).

Lepidagathis se distingue pelo cálice zigomófico, com cinco segmentos desiguais, corola bilabiada, lábio anterior 2-lobado e posterior 3-lobado, anteras anteriores sempre bitecas e posteriores, quando presentes, monotecas, bitecas ou vestigiais; pólen tricolporado e reticulado; disco nectarífero cupular, que cobre grande parte do ovário, e estigma subcapitado e 2-lobado (Kameyama 2008).

Lepidagathis kameyamana Gnanasek. \& Arisdason, Telopea 18: 389. 2015.

Erva 7-20 cm alt. Ramos híspidos. Folhas 3,9-6,5 × 2,5-4 cm, ovadas, esparsamente pilosas e híspidas nas nervuras de ambas as faces, margem ciliada, base decorrente, ápice mucronado; pecíolo 0,3-1,5 cm compr. Espiga terminal 1,8-4 cm compr., pedúnculo ca. $4 \mathrm{~mm}$ compr., 6-12 flores; brácteas obovadas, 6-8 $\times$ ca. $4 \mathrm{~mm}$, pilosas, margem ciliada; bractéolas lanceoladas, $8-9 \times$ ca. $1 \mathrm{~mm}$, ápice mucronado, margem ciliada. Flor subséssil, cálice $0,7-1 \mathrm{~cm}$ compr., segmentos desiguais, 6-9 $\times$ 0,5-1,5 mm, margem ciliada, pilosos, anterior e posterior oblanceolados, laterais estreito-triangulares; corola bilabiada, lilás, fauce alva, ca. $9 \mathrm{~mm}$ compr., tubo basal ca. $4 \mathrm{~mm}$ compr., lábio posterior ca. 3,5 ×4 mm; lábio anterior ca. $3,5 \times 5 \mathrm{~cm}$; estames 2 , exsertos, inseridos na fauce, 3,1-3,2 mm compr., inseridos a 3,3-3,4 $\mathrm{mm}$ da base da corola, anteras glabras, oblongas, 1-1,7 mm compr.; estilete ca. $6 \mathrm{~mm}$ compr, estigma capitado, ca. $0,2 \mathrm{~mm}$. Frutos não vistos.

Conforme material adicional examinado, Lepidagathis kameyamana floresce durante todo o ano (INCT 2017). Em Bertioga, foi encontrado material fértil coletado no mês de outubro.
No Brasil, a espécie ocorre na região Sudeste (Espírito Santo, Minas Gerais, Rio de Janeiro, São Paulo); no domínio fitogeográfico da Mata Atlântica, em Floresta Ombrófila (Flora do Brasil 2020 em construção).

Material examinado: BRASIL. SÃo PAUlo: Bertioga, Riviera de São Lourenço, 20-X-1999, S.E. Martins 569 (HUSC, SP).

Material adicional examinado: BRASIL. SÃo Paulo: Cananeia, Parque Estadual da Ilha do Cardoso, 6-III-1985, C.B. Toledo et al. 51 (SP); idem, 11-XI-1981, J.B. Baitello 62 (SPSF, SP); idem, 7-X-1980, S.L. Jung et al. 8570 (SP); idem, 24-V-1983, S.L. Jung-Mendaçolli \& E.A. Lopes 553 (SP); idem, 6-I-1982, M. Kirizawa et al. 684 (SP); idem, 30-X-1985, M. Kirizawa 1522 (SP); idem, 28-XI-1974, J. Mattos 16093 (SP); idem, 24-X-1989, I. Cordeiro et al. 618 (SP); idem, 14-IX-1983, S. Romaniuc Neto 89 (SP); idem, 7-IV-1982, M.R.O. Santos et al. 15 (SP); idem, 9-V-1990, S.J.G. Silva \& F. de Barros 4 (SP); idem, 21-VIII-1979, C.F.S. Muniz et al. 51 (SP).

\section{Ruellia L.}

Ruellia é um amplo gênero que conta com, aproximadamente, 350 espécies, com vasta distribuição tropical e subtropical. O Novo Mundo é o mais importante centro de diversidade do gênero (Ezcurra 1993, Tripp et al. 2013), que chega a atingir regiões temperadas nas Américas. Dentre os representantes brasileiros, ocorrem cerca de 80 espécies, com 44 endêmicas. No Estado de São Paulo, ocorrem 18 espécies (Flora do Brasil 2020 em construção). Ruellia e Justicia compõem, juntas, os gêneros mais bem representados quanto ao número de espécies em levantamentos regionais da família (Braz et al. 2002).

Os representantes do gênero são subarbustos, arbustos ou, mais raramente, pequenas árvores e lianas tropicais, subtropicais, ou ervas perenes de clima temperado; as flores podem ser leve ou fortemente zigomorfas; com quatro estames unidos na base por uma membrana estaminal, geralmente didínamos, com anteras bitecas, tecas paralelas e sem apêndice (Tripp 2007).

\section{Ruellia sp.}

Figuras 2 d-e, 3 f-g

Subarbusto 0,5-1,7 m alt. Ramos híspidos, podendo ocorrer tricomas tectores. Folhas (4,9-) 5,2-11 $\times$ (2,4-) 2,5-4 cm, elípticas, estreito-elípticas ou 
obovadas, ambas as faces híspidas ou face abaxial densamente híspida, tricomas concentrados nas nervuras, cistólitos presentes, margem ciliada, base atenuada, ápice agudo a atenuado; pecíolo $0,5-1,5 \mathrm{~cm}$ compr. Cimeira axilar ou terminal, 2-4,5 cm compr., pedúnculo 1,2-2,8 cm compr.; brácteas folhosas; bractéolas oblongo-lanceoladas a estreito elípticas, 1-7 (-8) × 1-1,5 mm. Pedicelo 5-8 mm compr.; cálice 1-3 × 0,5 cm, segmentos subiguais $2-2,5 \mathrm{~cm}$ compr., oblongo-espatulados, ápice obtuso, hirsutos externamente, sobretudo na base, glabros a pilosos internamente, cistólitos presentes, margem ciliada, unidos ca. 1-4 mm compr.; corola infundibuliforme, lilás, às vezes com a fauce creme ou lobos lilases e tubo creme-azulado, 3,5-6,8 cm compr., porção estreita do tubo 2-3,5 (4) cm compr., porção alargada do tubo $1-1,6 \mathrm{~cm}$, lobos $0,5-1,4 \times 0,5-1,4 \mathrm{~cm}$; estames inclusos, inseridos na fauce, os maiores $0,8-0,9 \mathrm{~cm}$ compr. e os menores $0,7-0,8 \mathrm{~cm}$ compr., anteras glabras, $3-3,5 \mathrm{~cm}$ compr.; estilete 2,5-4,5 cm compr., estigma bilobado, lobos arredondados a oblanceolados, desiguais, ca. 0,1, 0,2 mm compr.; disco nectarífero cupular. Cápsulas elipsoides, 2-2,2 cm compr.; sementes 4, ca. 4, $5 \mathrm{~mm}$ compr.,com tricomas higroscópicos por toda a superfície.

Em Bertioga, Ruellia sp. floresce ao longo de todo o ano (INCT 2017).

Material examinado: BRASIL. SÃo PAULO: Bertioga, Condomínio Guaratuba 2, 22-VIII-1995, M. Kirizawa et al. 3192 (SPF, SP); Fazenda da Família Pinto, 17-XI-1998, L. Rossi \& P.S.P. Sampaio 2020 (SP, HUSC, SPF); Itaguaré, Parque Estadual Restinga de Bertioga, trilha da praia de Itaguaré, 14-III-2015, R.K. Kojima 1 (HUSC); idem, Praia de Itaguaré, 27-V-1999, M.A.G. Magenta \& P.S.P. Sampaio 176 (HUSC, SP); S.E. Martins et al. 477 (HUSC, SP); idem, 28-VII-2000, M. Groppo Jr. 426 (SPF); idem, 26-XI-1998, S.E. Martins et al. 346 (HUSC, SP), idem, 14-I-1999, S.E. Martins et al. 376 (HUSC, SP); idem, 6-V-1999, M.A.G. Magenta et al. 140 (HUSC, $\mathrm{SP})$.

Material adicional examinado: BRASIL. SÃo PAULO: Cananeia, 1-VI-1982, M.M.R. Fiuza de Melo et al. 400 (SP); Ilha do Cardoso, 18-VIII-1982, F. Barros 773 (SP), idem, 3-VI-2005, F.O. Souza et al. 237 (SP), idem, 20-IV-1983, M. Kirizawa et al. 973 (SP); idem, 19-IV-1983, M. Kirizawa et al. 918 (SP); idem, 20-VI-1989, L. Rossi et al. 520 (SP); idem, 14-X-1986, M. Kirizawa et al. 1783 (SP); idem, 12-IX-1990, L. Rossi et al. 699 (SP); idem, Rio Jacareu, Morro
Jacareu, 9-X-1982, E. Forero et al. 8728 (SP); idem, 14-VI-1988, M. Sugiyama \& M. Kirizawa 745 (SP, US); idem, 10-VI-1986, M. Kirizawa 1639 (SP); idem, 19-IV-1983, M. Kirizawa et al. 963 (SP) idem, trilha de acealsso Andrades-João Cardoso, 11-V-1982, L.S.R. Duarte 51 (SP); Rio Sambaqui-Mirim, 2-VI-1982, M.M.R. Fiuza de Melo et al 407 (SP); Sete Barras, Faz. Intervales, 27-VII-1994, M. Sugiyama \& M. Kirizawa 1212 (SP); 13-V-1993, M. Kirizawa et al. 2825 (SP).

Dentre os táxons encontrados no PERB, Avicennia schaueriana pertence à subfamília Avicennioideae. A maioria dos demais táxons pertencem à subfamília Acanthoideae, a mais comum em Acanthaceae, que se distingue pela presença de frutos com deiscência explosiva e retináculos nas sementes (Scotland \& Vollesen 2000). Entre os gêneros, Aphelandra pertence à tribo Acantheae, Justicia, à tribo Justiceae, Lepidagathis à tribo Barleriae e os demais, à tribo Ruellieae.

Para a área de entorno do Parque foram encontrados registros de coletas de Mendoncia velloziana Mart, sempre próximo a áreas antropizadas, como em beira de estradas e áreas habitadas. $M$. velloziana é trepadeira, com folhas opostas. Suas flores apresentam na base um par de bractéolas vermelhas bem desenvolvidas que cobrem o botão floral e parcialmente a corola, o cálice é reduzido a um anel, a corola vermelha e tubulosa.

Também foi encontrada recentemente na área estudada e em seu entorno, Brillantaisia lamium (Nees), como invasora em áreas abertas na vegetação de restinga. Esta espécie é nativa da África tropical e do Madagascar. É uma planta herbácea, ereta e ocasionalmente volúvel. Suas flores são bilabiadas e têm coloração azul purpúreo. B. lamium não foi tratada nesse estudo por sua origem exótica.

Uma constatação relevante, observada em campo, foi a de que formas variegadas e não-variegadas de Aphelandra ornata, podem apresentar ocorrência simpátrica na área de estudo. O gênero Aphelandra foi o que apresentou ocorrência mais comum em Bertioga.

Em estudo feito na Ilha do Cardoso, Cananeia, no Estado de São Paulo, apenas na área delimitada pela vegetação de restinga, Kameyama \& Hirao (2015) registraram a ocorrência de Ruellia, e quatro espécies em comum com as do Parque Estadual Restinga de Bertioga - PERB: Aphelandra ornata, Justicia carnea, J. schenckiana (tratada como Justicia sp) e Lepidagathis kameyamana. Moura et al. (2007), em estudo de levantamento realizado no município de São Vicente, SP, registraram a ocorrência de Ruellia, 
gênero também encontrado em Bertioga, além de Aphelandra prismatica e Avicennia schaueriana, espécies em comum com aquelas registradas para Bertioga. Em formações de restinga da Marambaia RJ, Braz \& Azevedo (2016) realizaram o levantamento florístico e encontraram representantes de Schaueria, gênero não registrado em Bertioga, Aphelandra, Justicia e Ruellia, com espécies distintas daquelas citadas por Martins et al. (2008) e também não encontradas no PERB; em manguezal, os autores encontraram Avicennia schaueriana, espécie também encontrada em Bertioga. Nas restingas de Maricá - RJ (Silva \& Oliveira 1989), foram encontrados apenas representantes de Thunbergia L. e Justicia, esse último gênero também encontrado em Bertioga, porém sem registros de espécies em comum. Pereira \& Araújo (2000) compilaram os dados de levantamento florístico de seis áreas do Espírito Santo e nove áreas do Rio de Janeiro, listando para Acanthaceae três gêneros de ocorrência no primeiro Estado (Aphelandra, Mendoncia Vell. ex Vand. e Ruellia) e sete no Rio de Janeiro (Aphelandra, Justicia, Pseuderanthemum Radlk. ex Lindau, Ruellia, Schaueria Nees e Stenostephanus Nees); houve o registro de Aphelandra prismatica, espécie em comum com a encontrada em Bertioga. Braz et al. (2013) encontraram cinco espécies na Restinga de Praia das Neves, ES, com três gêneros em comum com o PERB (Avicennia, Justicia e Ruellia), sendo que a única espécie encontrada nos dois locais foi $A$. schaueriana.

Nesses estudos, foram registradas no total 46 espécies de Acanthaceae abrangidas pelas restingas do Sudeste, e 16 espécies nas restingas de São Paulo. A Ilha do Cardoso - SP (Kameyama \& Hirao 2015), foi a que apresentou maior similaridade em composição de espécies com o PERB. Os novos registros para a restinga do Estado de São Paulo, a partir dos dados obtidos deste estudo, são Herpetacanthus rubiginosus e Hygrophila costata.

Em Bertioga, há uma fisionomia não categorizada pela classificação adotada na Resolução CONAMA n. 07/96, que difere da Floresta Paludosa sobre Substrato Turfoso pelo regime de inundação, que é temporário nessa cidade, e pela ausência de turfeiras; essa fisionomia foi chamada de Floresta Alta de Restinga Úmida por Souza (2006). Existem, ainda, outras fisionomias encontradas na região de Bertioga não enquadradas na classificação da Resolução do CONAMA; nessas formações, podem ocorrer variações na caracterização do substrato, como espessura da camada de serrapilheira (como no Escrube e na Floresta Alta de Restinga) e presença de turfa, assim como diferenças no regime de inundação e variação no padrão florístico (como na Floresta Alta de Restinga). Dentre as espécies de Acanthaceae abordadas nesse estudo, B. lamium, J. schenckiana e Ruellia sp foram encontradas na Floresta Alta de Restinga; H. rubiginosus e L. kameyamana, na Vegetação entre Cordões Arenosos; na Floresta Alta de Restinga Úmida, quase todas as espécies foram registradas, exceto $B$. lamium e $J$. schenckiana.

Os resultados aqui apresentados representam o primeiro estudo detalhado de Acanthaceae das restingas da região central do litoral paulista, e abrem caminho para que novas investigações sejam feitas para as espécies do ambiente de restinga.

\section{Agradecimentos}

Ao CNPq, pela bolsa de iniciação científica concedida, à Universidade Santa Cecília; aos curadores dos herbários HUSC, SP, SPF e UEC pelo auxílio e autorização à consulta aos materiais citados; à Fundação Florestal pela autorização de coleta, ao Carlos Venicio Cantareli, Paulo S. Penteado Sampaio, Larissa Brandine Nascimento, Mara A.G. Magenta, Suzana E. Martins e Ulisses G. Fernandes, pelas fotografias concedidas; aos dois revisores anônimos que, graças às suas detalhadas $\mathrm{e}$ rigorosas sugestões, ajudaram a melhorar o manuscrito.

\section{Literatura citada}

APG (The Angiosperm Phylogeny Group). 2016. An update of the Angiosperm Phylogeny Group classification for the orders and families of flowering plants: APG IV. Botanical Journal of the Linnean Society 181: 1-20.

Araújo, D.S.D. 1984. Comunidades vegetais. In: L.D. Lacerda, D.S.D.Araújo, R. Cerqueira \& B. Turq (orgs.). Restingas; origem, estrutura, processos. CEUFF, Niterói.

Araújo, D.S.D. \& Henriques, R.P.B. 1984. Análise florística das restingas do Estado do Rio de Janeiro. In: L.D. Lacerda, D.S.D. Araújo, R. Cerqueira \& B. Turq (orgs.). Restingas; origem, estrutura, processos. CEUFF, Niterói, pp. 159-193.

Assis, M.A., Prata, E.M.B., Pedroni, F., Sanchez, M., Eisenlohr, P.V., Martins, F.R., Santos, F.A.M., Tamashiro, J.Y., Alves, L.F. Vieira, S.A., Piccolo, M.C., Martins, S.C., Camargo P.B., Carmo, J.B. Simões, E., Martinelli, L.A. \& Joly, C.A. 2011. Florestas de restinga e de terras baixas na planície costeira do sudeste do Brasil: vegetação e heterogeneidade ambiental. Biota Neotropica 11: 103-121. Disponível em http://www.scielo.br/scielo.php?script $=$ sci arttext\&pid $=$ S1676-06032011000200012\&lng $=$ en (acesso em 19-VIII-2017). 
Borg, A.J., McDade, L.A. \& Schönenberger, J. 2008. Molecular Phylogenetics and Morphological Evolution of Thunbergioideae (Acanthaceae). Taxon 57: 811-822.

Braz, D.M., Carvalho-Okano, R.M., Kameyama, C. 2002. Acanthaceae da Reserva Florestal Mata do Paraíso, Viçosa, Minas Gerais. Revista Brasileira de Botânica 25: 495-504.

Braz, D.M. \& Azevedo, I.H.F. 2016. Acanthaceae da Marambaia, Estado do Rio de Janeiro, Brasil. Hoehnea 43: 497-516.

Braz D.M., Jacques E.L., Somner G.V., Sylvestre L.S., Rosa M.M.T., Moura M.V.L.P., Filho P.G., Couto A.V.S. \& Amorim T.A. 2013. Restinga de Praia das Neves, ES, Brasil: caracterização fitofisionômica, florística e conservação. Biota Neotropica 13: 314-331.

Brummitt, R.K. \& Powell, C.E. 1992. Authors of Plant Names. Kew. Royal Botanic Gardens.

Cerqueira, R. 2000. Biogeografia das Restingas. In:F.A. Esteves \& L.D. Lacerda (eds.). Ecologia de restingas e lagoas costeiras. Macaé: NUPEN / UFRJ, pp. 65-75.

CONAMA- Conselho Nacional do Meio Ambiente. 1996. Anexo da Resolução CONAMA 07/96, de 23 de julho de 1996. Diário Oficial da União, Brasília.

Daniel, T.F. 1995. Acanthaceae. In: D.E. Breedlove (ed.). Flora of Chiapas. California Academy of Sciences, San Francisco 4: 1-158.

Durkee, L.H. 1986. Acanthaceae. In: W. Burger (ed.). Flora Costaricensis, Family 200. Fieldiana, Botany 18: 47.

Ezcurra, C. 1993. Systematics of Ruellia (Acanthaceae) in Southern South America. Annals of the Missouri Botanical Garden 80: 787-845.

Ezcurra, C. 2002. El género Justicia (Acanthaceae) em Sudamérica Austral. Annals of the Missouri Botanical Garden 89: 225-280.

Flora do Brasil 2020 (em construção). 2018. Jardim Botânico do Rio de Janeiro. Disponível em http:// floradobrasil.jbrj.gov.br/reflora/floradobrasil/FB33 (acesso em 22-VIII-2018).

Fundação Florestal. Disponível em http://fflorestal.sp.gov. br/ (acesso em 10-IV-2017).

Graham, V.A.W. 1988. Delimitation and infra-generic classification of Justicia (Acanthaceae). Kew Bulletin 43: 551-624.

INCT - Herbário Virtual da Flora e dos Fungos. 2017. Disponível em http://inct.splink.org.br/ (acesso em 14-VI-2017).

Indriunas, A. \& Kameyama, C. 2012. New Species of Herpetacanthus (Acanthaceae) from the Atlantic Forest and Neighboring Areas (Brazil). Systematic Botany 37: 1006-1022.

Judd, W.S., Campebell, C.S., Kellog, E.A., Stevens, P.F., Donoghue M.J. 2009. Sistemática vegetal: um enfoque filogenético. 3.ed. Artemed, Porto Alegre.
Kameyama, C. 2008. New species, nomenclatural changes and lectotypifications in neotropical Lepidagathis Willd. (Acanthaceae). Kew Bulletin 63: 565-581.

Kameyama, C. \& Hirao, Y.V. 2015. Flora Fanerogâmica da Ilha do Cardoso (São Paulo, Brasil). Acanthaceae. In: M.M.R.F. Melo, F. Barros, S.A.C. Chiea, S.L. Jung-Mendaçolli, M.G.L. Wanderley, (org.). Flora Fanerogâmica da Ilha do Cardoso. 1 ed. Instituto de Botânica, São Paulo, v. 16, pp. 185-202.

Kiel, C. A., Daniel, T. F., Darbyshire, I., McDade, L.A. 2017. Unraveling relationships in the morphologically diverse and taxonomically challenging "Justicioid" lineage (Acanthaceae: Justicieae). Taxon 66: 645-674.

Lacerda, L.D. \& Esteves, F.A. 2000. Apresentação Restingas brasileiras: 15 anos de estudos. In: F.A. Esteves \& L.D. Lacerda (eds.). Ecologia de restingas e lagoas costeiras. NUPEM/UFRJ, Macaé, pp. 2-7.

Lioger, A.H. 1997. Descriptive Flora of Puerto Rico and Adjacent Islands: Spermatophyta. La Editorial, UPR.

Magnagago, L.F.S., Martins, S.V., Pereira, O.J. 2011. Heterogeneidade florística das fitocenoses de restingas nos Estados do Rio de Janeiro e Espírito Santo, Brasil. Viçosa, MG: Revista Árvore 35: 245-254.

Martins, S.E., Rossi, L., Sampaio, P.S.P., Magenta, M. A.G. 2008. Caracterização Florística de comunidades vegetais de restinga em Bertioga, SP, Brasil. Acta Botanica Brasilica. 22: 249-274.

Mcdade, L.A., Daniel, T.F., Masta, S.E., Riley, K.M. 2000. Phylogenetic Relationships within the Tribe Justicieae (Acanthaceae): Evidence from Molecular Sequences, Morphology and Citology. Annals of the Missouri Botanical Garden 87: 435-458.

Mcdade, L.A., Daniel, T.F., Kiel, C.A. 2008. Toward a Comprehensive Understanding of Phylogenetic Relationships Among Lineages of Acanthaceae S.L. (Lamiales). American Journal of Botany 95: 1136-1152.

Moura, C., Pastore, J.A., Franco, G.A.D.C. 2007. Flora vascular do Parque Estadual Xixová-Japuí, Setor Paranapuã, São Vicente, Baixada Santista, SP. Revista do Instituto Florestal 19: 149-172.

Pereira, O.B. \& Araújo, D.S.D. 2000. Análise florística das restingas dos Estados do Espírito Santo e Rio de Janeiro. In: F.A. Esteves \& L.D. Lacerda (eds.). Ecologia de Restingas e Lagoas Costeiras. NUPEN/UFRJ, Macaé, pp. 25-63.

Profice, S.R. \& Andreata, R.H.P. 2011. Revisão taxonômica de Aphelandra R. Br. (Acanthaceae) de corola curto-bilabiada. Pesquisas, Botânica 62: 7-70.

Schwarzbach, A.E. \& McDade, L.A. 2002. Phylogenetic relationship of the mangrove family Avicenniaceae based on chloroplast and nuclear ribosomal DNA sequences. Systematic Botany 27:84-98. 
Scotland, R.W. \& Vollesen, K. 2000. Classification of Acanthaceae. Kew Bulletin 55: 513-589.

Silva, J.G. \& Oliveira, A.S. 1989. A vegetação de restinga no município de Maricá-RJ. Acta Botanica Brasilica 3: 253-272.

Souza, C.R.G. 2006. Mapeamento de compartimentos fisiográficos de planície costeira e baixa-encosta e da vegetação associada, no Litoral Norte de São Paulo. In: VI Simpósio Nacional de Geomorfologia. Goiânia, UGB.

Stevens, P.F. 2001. Angiosperm Phylogeny Website. Version 14, July 2017 [and more or less continuously updated since]. Disponível em http://www.mobot. org/MOBOT/research/APweb/ (acesso em 10-III2017).

Tomlinson, P.B. 1986. The botany of mangroves. Cambridge University, New York.
Tripp, E.A. 2007. Evolutionary Relationships Within the Species-Rich Genus Ruellia (Acanthaceae). Systematic Botany, by the American Society of Plant Taxonomists 32: 628-649.

Tripp, E.A., Daniel, T.F., Fatimah, S., McDade, L.A. 2013. Phylogenetic Relationships within Ruellieae (Acanthaceae) and a Revised Classification. International Journal of Plant Sciences 174: 97-137.

Wasshausen, D.C. 1975. The Genus Aphelandra (Acanthaceae). Smithsonian Contributions to Botany, City of Washington, n. 18.

Wasshausen, D.C. \& Smith, L.B. 1969. Acantáceas. In: R. Reitz (ed.). Flora ilustrada Catarinense. Santa Catarina, Herbário Barbosa Rodrigues.

Zaluar, H.L.T. \& Scarano, F.R. 2000. Facilitação em Restingas de Moitas: Um Século de Buscas por Espécies Focais, pp. 3-23. In: F.A. Esteves, L.D. Lacerda (eds.). Ecologia de Restingas e Lagoas Costeiras. NUPEN/ UFRJ, Macaé, pp. 25-63. 